\title{
Complutum
}

ISSN: 1131-6993

\section{Las comunidades medievales de villa y tierra: ¿una analogía válida para la Protohistoria Final? ${ }^{1}$}

\author{
Manuel Fernández-Götz²; Raquel Liceras-Garrido ${ }^{3}$
}

Recibido: 30 de enero de 2019 / Aceptado: 25 de abril de 2019

Resumen. Los mecanismos sociales que articularon las sociedades de la Edad del Hierro siguen siendo difíciles de comprender. En las últimas décadas, los modelos piramidales tradicionales han sido cuestionados por varios autores que abogan por la diversidad de las sociedades de la Edad del Hierro y la heterogeneidad de formas potenciales de configuración social. Crucial para la mayoría de los debates es el uso de analogías, con algunos autores que favorecen las fuentes históricas de la Europa medieval, mientras que otros privilegian ejemplos etnográficos de áreas alejadas del continente europeo. Si bien consideramos que ambos enfoques son legítimos, en este trabajo presentamos el ejemplo de las comunidades de "villa y tierra" medievales, particularmente el caso de Soria. Estas comunidades muestran un modelo de relaciones de parentesco, basado en estructuras organizativas transversales, que pueden ayudarnos a comprender los lazos y vínculos entre los habitantes de un paisaje según sus orígenes, lugar de residencia o familia. Por ello, argumentamos que la comunidad de villa y tierra de Soria podría servir como una analogía útil, aunque no una comparación directa, para conceptualizar las interrelaciones entre las áreas urbanas y rurales, así como para examinar la estructuración simultánea de grupos sociales en torno a los principios de parentesco y territorialidad en un contexto de urbanización emergente.

Palabras clave: Edad del Hierro; Modelos Sociales; Analogías; Asambleas; Oppida; Comunidad de Villa y Tierra.

\section{[en] The medieval town and land communities: A valid analogy for Late Protohistory?}

Abstract. The social mechanisms that articulated Iron Age societies are still difficult to understand. In the last decades, the traditional pyramidal models have been questioned by different authors who advocate for the diversity of Iron Age societies and the heterogeneity of potential forms of social configuration. Crucial for most of the debates is the use of analogies, with some authors who favour historical sources from medieval Europe and others who privilege ethnographical examples from outside the European continent. While we consider both approaches legitimate, in this paper we present the example of the medieval "town and land" communities, in particular the case of Soria. These communities show a model of kinship relationships, based on transversal organisational structures, which can help us understand the ties and connections between the inhabitants of a landscape according to their origins, place of residence or family. Thus, we argue that the town and land community from Soria can serve as a useful analogy, although not a direct comparison, in order to conceptualise the interrelationships between the urban and rural areas, as well as for examining the simultaneous structuration of social groups around the principles of kinship and territoriality in a context of emerging urbanisation.

Keywords: Iron Age; Social Models; Analogies; Assemblies; Oppida; Town and Land Community.

Sumario: 1. Introducción. 2. Debatiendo los modelos de organización protohistóricos. 3. Modelos vecinales, asambleas y ciudades: Redes sociales en la Edad del Hierro. 4. El surgimiento de las ciudades: los oppida como espacios de agregación. 5. Reflexiones finales. 6. Bibliografía.

1 Este artículo ha sido redactado con el apoyo del Philip Leverhulme Prize y durante una estancia de investigación del primer autor en el Joukowsky Institute for Archaeology de la Universidad de Brown.

2 School of History, Classics and Archaeology, University of Edinburgh M.Fernandez-Gotz@ed.ac.uk

3 Digital Humanities Hub - History Department, Lancaster University. r.liceras@lancaster.ac.uk 
Cómo citar: Fernández-Götz, M.; Liceras-Garrido, R. (2019): Las comunidades medievales de villa y tierra: ¿Una analogía válida para la Protohistoria Final? Complutum, 30(1): 179-196.

\section{Introducción}

Los últimos siglos antes del cambio de Era fueron un período de profundos cambios en numerosas regiones de Europa, materializados en aspectos como el desarrollo de las ciudades fortificadas conocidas como oppida y la expansión de las redes sociopolíticas y económicas. En este trabajo, nuestro objetivo es triple: 1) resumir algunos de los debates actuales sobre los modelos sociales de la Edad del Hierro, 2) discutir los diferentes niveles de agregación de las sociedades del Hierro final y su forma de organización a través de asambleas y lugares centrales, y 3) presentar el ejemplo histórico de las comunidades de "villa y tierra" medievales, particularmente el caso de Soria, como posible analogía que puede ayudarnos a mejorar la comprensión de las interconexiones entre los grupos de parentesco, las ciudades y el mundo rural.

En lugar de proporcionar respuestas definitivas, hemos concebido este artículo como un conjunto de modelos y cuestiones sobre las que reflexionar. Si bien nunca estaremos completamente seguros acerca de "cómo funcionaron las sociedades de la Edad de Hierro" - parafraseando el título del trabajo de J. D. Hill (2006) -, deberíamos continuar el esfuerzo de proponer nuevos modelos basados en enfoques interdisciplinares.

\section{Debatiendo los modelos de organización protohistóricos}

La noción tradicional de una sociedad celta, bastante homogénea, caracterizada como un "triángulo" con élites en la cima de la pirámide social, ha sido cuestionada en las últimas décadas por nuevos modelos que enfatizan la diversidad de las sociedades de la Edad del Hierro y las variaciones que existieron a través del tiempo y el espacio (Collis 1994; Hill 2006; Hill y Cumberpatch 1993; Ruiz Zapatero 2017; Ruiz Zapatero y Fernández-Götz 2009; Sastre 2002; Thurston 2009). En particular, la insatisfacción con el modelo jerárquico tradicional "triangular" ha llevado a desarrollar formas alternativas de entender las comunidades protohistóricas, siendo una de las más influyentes la propuesta de J. D. Hill (2006) de sociedades "rectangulares" y "trapezoidales", en las que habría existido poca distancia social entre los miembros de la comunidad y donde una proporción significativa de la población total formaría parte del escalafón más alto (Figura 1). En algunos casos, no obstante, el reciente énfasis en la literatura académica sobre la existencia de jerarquías sociales "planas" en la Edad del Hierro parece estar reemplazando al modelo monolítico de sociedades guerreras jerárquicas "triangulares", por otra conceptualización igualmente simplista y estática en el que habría poca o ninguna diferenciación social antes de la conquista romana. En lugar de favorecer un modelo conceptual sobre otro basado en un conjunto de a prioris teóricos, lo que necesitamos son más estudios contextuales que tomen en cuenta la variabilidad regional y temporal de las formaciones sociales, ya que existieron diferentes tipos de comunidades con una amplia variedad de configuraciones sociales, asentamientos y patrones de enterramiento, ideologías, etc. que habrían coexistido e interactuado. 


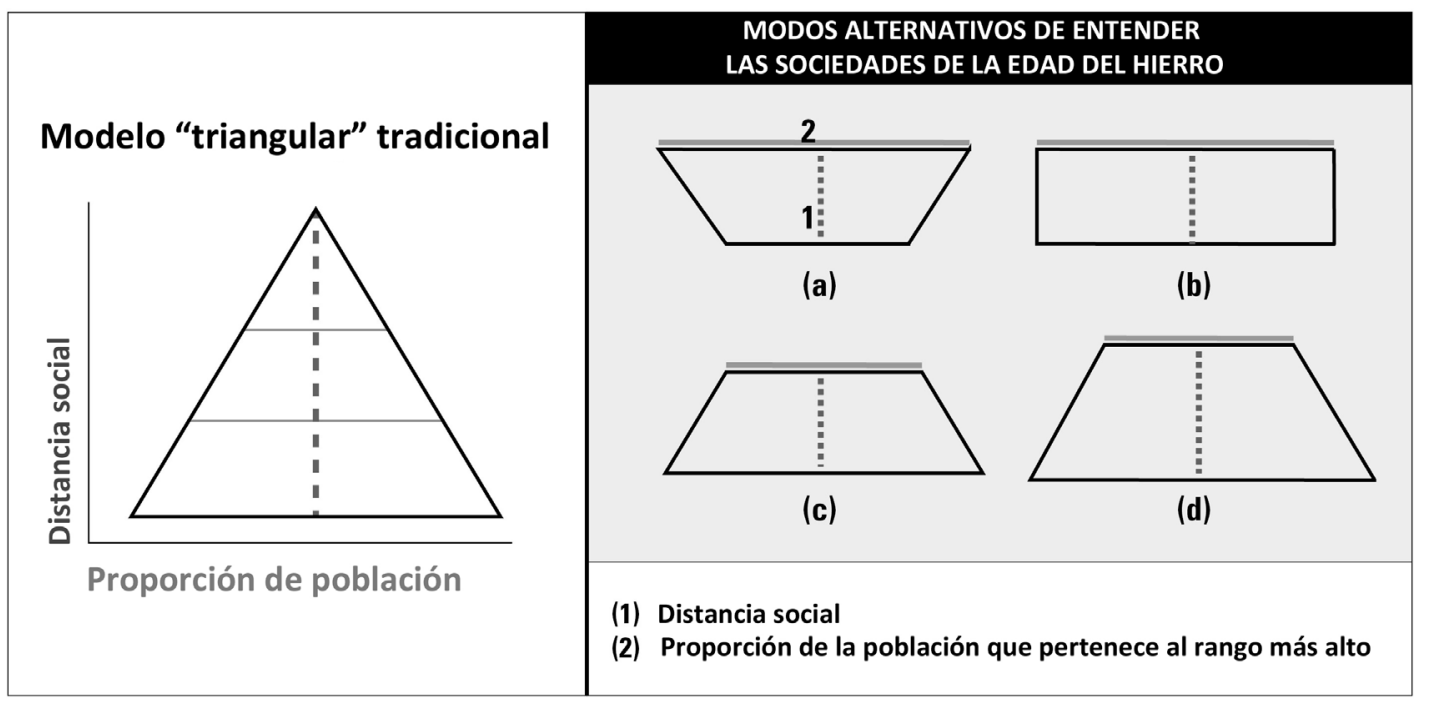

Figura 1: Modelo tradicional "triangular" de organización social y formas alternativas de concebir las sociedades de la Edad del Hierro (según Fernández-Götz, a partir de Hill 2006).

No hubo, en todo caso, una sociedad uniforme en la Edad del Hierro, sino varias sociedades sujetas a cambios a lo largo del tiempo. Los "asentamientos principescos" (Fürstensit$z e)$ del siglo VI a.n.e. de la Europa templada, por ejemplo, tenían desigualdades sociales mucho más marcadas y un mayor grado de centralización que sus homólogos contemporáneos en las tierras altas del Duero o de los montes Peninos británicos. Además, se ha hecho cada vez más evidente que, a escala europea, no existe una evolución continua o lineal de formas más descentralizadas e igualitarias a otras más centralizadas y jerárquicas. En cambio, sociedades altamente jerárquicas que podrían corresponder con una especie de modelo "triangular", como es el caso de Fürstensitze hallstátticos, experimentaron episodios de crisis o incluso colapso que fueron seguidos por un retorno a patrones más heterárquicos y descentralizados (Fernández-Götz 2017). Si bien los desencadenantes específicos de esos episodios no siempre son muy claros, parece que al menos una parte de ellos se relaciona con estrategias destinadas a contrarrestar el desarrollo excesivo de las desigualdades sociales y la centralización, siguiendo el famoso trabajo de P. Clastres (1980) sobre "sociedades contra el Estado" (véanse, por ejemplo, González García 2017 para una aplicación al noroeste hispano y Fernández-Götz 2014a para una visión desde Centroeuropa). Los resultados a menudo se pueden conceptualizar en el marco de las "sociedades descentralizadas" apuntadas, entre otros autores, por M. Mann: "Further general processes were 'devolutions' - movement back toward rank and egalitarian societies - and a cyclical process of movement around these structures, failing to reach permanent stratification and state structures. In fact, human beings devoted a considerable part of their cultural and organizational capacities to ensure that further evolution did not occur" (Mann 2012: 39).

Dos cuestiones clave que subyacen, implícita o explícitamente, en muchas de las discusiones sobre los modelos sociales de la Edad de Hierro son las escalas de análisis y la naturaleza de las analogías. Respecto a las primeras, una serie de estudios han adoptado macro-modelos basados en la Teoría de los Sistemas-Mundo de I. Wallerstein (Wallerstein 1974; ver también Kümmel 2001), incluyendo el famoso artículo de S. Frankenstein y M. Rowlands (1978) sobre las economías de bienes de prestigio para el período final de Hallstatt; la monografía de P. Brun (1987) sobre las interacciones entre el Mediterráneo y Europa Central en la temprana Edad de Hierro; y el trabajo de C. Haselgrove (1987) sobre el impacto romano en la Galia Bélgica. Del mismo modo, otros autores han preferido centrarse en los modelos de "economía doméstica" a pequeña escala, como es el caso de Hill (1995) sobre la Edad del Hierro en la zona de Wessex. Sin querer participar en una discusión sobre 
las interpretaciones específicas presentadas por los diferentes autores, ambos enfoques macro y micro - son complementarios, ya que se centran en diferentes escalas de análisis.

Más escasos son, por ahora, los modelos que intentan cerrar la brecha entre los niveles macro y lo micro. En este sentido, resulta ejemplar el modelo de redes sociales propuesto por R. Karl (2015). El autor apunta que fue la combinación de una base microeconómica formada por unidades domésticas, familias y vecindarios y la superestructura macroeconómica de las relaciones señor-criado, que a su vez conectan las diversas unidades microeconómicas, la que permitió obtener la mano de obra necesaria tanto para llevar a cabo pequeñas tareas locales, como para aquellas de mayor envergadura que exigiesen una mano de obra intensiva. En este sentido, es fundamental para su propuesta el reconocimiento de que existieron tanto redes "igualitarias" de apoyo vecinal como otras jerárquicas que operaban simultáneamente. Expandiendo este modelo, podríamos decir que las redes horizontales de tipo vecinal debieron existir en todas las comunidades protohistóricas, pues resultan básicas para su funcionamiento (Torres-Martínez 2014), mientras que la presencia de redes jerárquicas y su intensidad debió fluctuar entre unas sociedades y otras (Figura 2). Volviendo al modelo propuesto por Karl, es importante reseñar que se apoya principalmente en las fuentes escritas de la Edad Media irlandesa y galesa, lo que nos lleva a considerar el papel de las analogías y su elección.

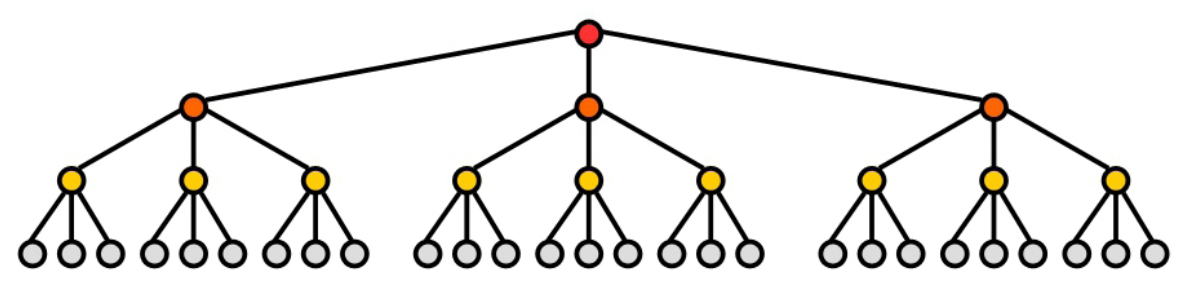

Figura 2: Modelo teórico de red jerárquica (según Karl 2015).

Toda interpretación arqueológica se basa, hasta cierto punto, en la analogía, ya sea consciente y explícita o inconsciente e implícita (Gramsch 2000; Ickerodt 2010). En los estudios de la Edad del Hierro, se puede observar una cierta división entre los autores que recurren a las fuentes escritas antiguas y medievales - desde las descripciones de la sociedad homérica a los textos medievales de Irlanda y Gales - como su principal fuente de inspiración (por ejemplo Karl 2006, 2017) y aquellos que prefieren referencias etnográficas de fuera de Europa (véase Eggert 1988). Los primeros enfatizan la ventaja de la cercanía espacial y cultural de sus referencias - en el caso de las fuentes medievales de Irlanda y Gran Bretaña basándose sobre todo en las similitudes lingüísticas y los presuntos vínculos entre sociedades consideradas "celtas" -, así como en ciertas evidencias textuales y materiales que sugieren continuidades en prácticas religiosas, el derecho consuetudinario, la propiedad de la tierra o la herencia. Esta última línea de investigación tiene una larga tradición en la investigación española, que ha desarrollado algunos trabajos ciertamente notables (véanse, por ejemplo, Almagro Gorbea 1995: 50-60, 2006, 2017; Almagro Gorbea y Almagro Vidal 2012; Balbín Chamorro 2013; Moya 2013: 163-176). Por otro lado, los partidarios de la etnografía extra-europea a menudo condenan la naturaleza "etnocéntrica" de las comparaciones insulares y la falsa impresión de "familiaridad" en el uso de fuentes clásicas y medievales, defendiendo que los ejemplos de fuera de Europa pueden proporcionar una perspectiva más refrescante y menos tendenciosa. Sin embargo, ambos enfoques no son - o al menos no deberían ser - mutuamente excluyentes, sino que más bien deben verse como potencialmente complementarios. En este trabajo pretendemos aumentar el elenco de analogías empleadas, al introducir el modelo de la comunidad de villa y tierra de Soria en la Edad Media. Pero antes esbozaremos algunos de los mecanismos de relación y agregación presentes en la Edad del Hierro de la Europa templada. 


\section{Modelos vecinales, asambleas y ciudades: Redes sociales en la Edad del Hierro}

¿Cómo funcionaron las sociedades protohistóricas? Teniendo en cuenta la heterogeneidad de las formaciones sociales que hemos discutido anteriormente, podemos afirmar que no hay una respuesta general para esta pregunta. Sin embargo, existen ciertas características comunes $\mathrm{o}$, al menos, aspectos que la mayoría de las comunidades de la Edad del Hierro compartieron. Entre ellas, podemos citar la existencia de diferentes niveles superpuestos de organización sociopolítica. En el caso de la Galia del siglo I a.n.e., por ejemplo, las fuentes escritas - particularmente César - describen la existencia de cinco niveles principales de agregación social en orden ascendente: 1) hogares; 2) familias extensas (clanes); 3) comunidades subétnicas como los cuatro pagi de los Helvecios; 4) comunidades étnicas (civitates) como los Eduos, Arvernos o Tréveros; y 5) macro-categorías como los Belgas o Aquitanos (ver referencias y discusión en Fernández-Götz 2014a; Fichtl 2012; Roymans 1990; Verger 2009). Todos estos diferentes niveles coexistieron al mismo tiempo, aunque su importancia en la vida diaria varió considerablemente según las circunstancias del momento. De este modo, mientras hogares y familias extensas habrían desempeñado posiblemente el papel más relevante en la vida cotidiana, otros niveles superiores de agregación social podrían activarse y mostrarse más prominentes en épocas concretas del año o en circunstancias específicas, como un escenario de guerra.
La existencia de estos niveles superpuestos de agregación obviamente no era exclusiva de la antigua Galia, y estructuras de naturaleza similar también se encuentran en otras regiones, por ejemplo, en el norte de la Península Ibérica con escalas como Desonci - Zoelae - Astures o Pembeli - Orgenomesci - Cántabros (Peralta 2003; Torres-Martínez 2011) que son comparables a la estructura gala de familia extendida - pagus - civitas. Por su parte, en la Meseta oriental hispana podemos distinguir, gracias a autores como Plinio, Estrabón, Apiano y Polibio, toda una serie de agrupaciones políticas e identitarias supra-locales: 1) aquellas relacionadas con las entidades territoriales reunidas en torno a la figura de ciudades-estado como Segeda; 2) comunidades étnicas o tribus como Arévacos, Pelendones, Titos, Belos o Lusones; 3) redes étnicas de ayuda y cooperación en momentos de necesidad como las que existieron entre Numancia y Segeda; 4) y macro-categorías como los Celtíberos, cuyas implicaciones y significados cambiaron a lo largo del tiempo (cf. Burillo 2008; Liceras-Garrido en prensa). Además de los niveles sociopolíticos superpuestos mencionados anteriormente, también debemos tener en cuenta la existencia de elementos transversales como facciones políticas diferentes (a veces incluso dentro de los propios grupos familiares), otros tipos de identidad social como el género y los grupos de edad, complejas redes clientelares a diferentes escalas, reglas de honor que gobiernan las relaciones sociales, o mediadores religiosos como los druidas (Figura 3).

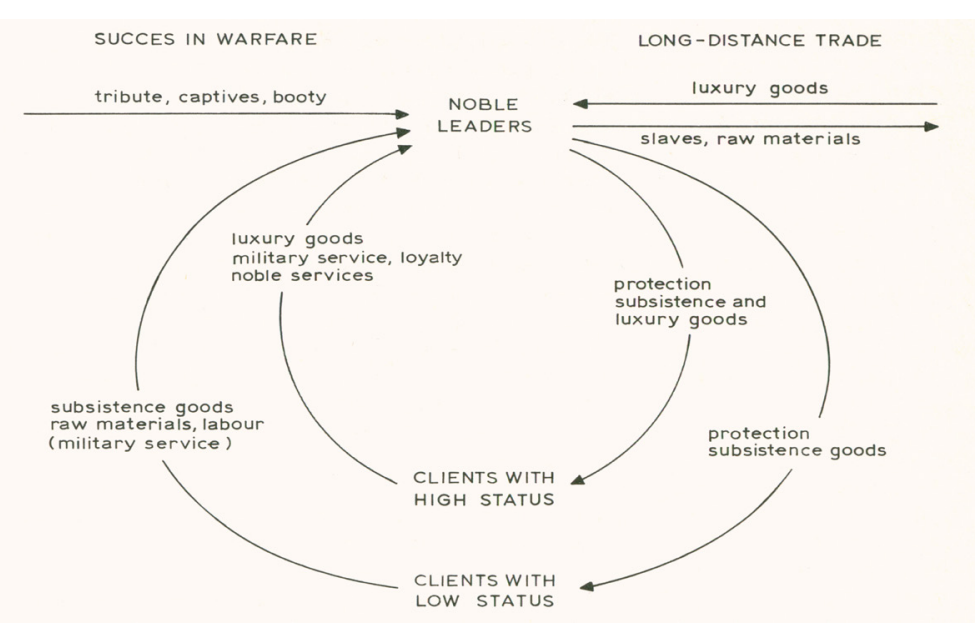

Figura 3: Esquema de relaciones patrono - cliente en la Galia del siglo I a.n.e. (según Roymans 1990). 
Independientemente de su significado en el mundo clásico, en el contexto de la Galia prerromana, la mejor definición de pagi y civitates es la sugerida por Gerritsen y Roymans (2006) quienes las definen como identidades étnicas politizadas, es decir, grupos étnicos que funcionan como comunidades políticas. Eran principalmente Personenverbände, es decir, grupos de personas con una identidad común basada en lazos ficticios de parentesco y la creencia de descendencia de un ancestro común, el "héroe fundador" o "padre del pueblo" (Teutates, derivado de *teutā- cuyo significado es tribu, personas, ver Almagro Gorbea y Lorrio 2011). Como ejemplo, dos de los tres nombres de pagi helvecios que conocemos estaban formados por un nombre personal más el sufijo-genus: Verbigenus y Toygeni. Estos serían muy probablemente los nombres de los héroes fundadores que dieron su nombre a cada uno de los grupos respectivos, similar a las 12 tribus de Israel que llevaban los nombres de los hijos de Jacob (Fernández-Götz 2013a). También existen indicios de que un sistema ideológico similar funcionó a menor escala para los grupos familiares extensos, ya que en la zona del Rin tenemos inscripciones de época romana con nombres como $\mathrm{Ge}$ sationes (derivado de Gesatus), Arvagastae (de Arvagast) y Albiahenae (de Albius) (Bauchhenss 2007; Roymans 1990). Estos nombres podrían referirse a los fundadores míticos o reales de los respectivos grupos familiares extendidos, lo que implicaría que cada grupo adoraba a su propio "héroe fundador".

Como puede apreciarse, el parentesco - real o metafórico - y las concepciones de descendencia ligadas a él desempeñaban un papel esencial en la estructuración de las relaciones sociales. Por citar sólo dos ejemplos del ámbito galo, los Ambarros eran considerados amigos de los Eduos y de la misma sangre que éstos (consanguinei, BG I, 11, 4), mientras que los Remos consideraban a los Suesiones fratres consanguineosque suos (BG II, $3,5)$. Las sociedades protohistóricas - o al menos la mayor parte de ellas - parecen haber estado ordenadas en buena medida por el parentesco (García Quintela 2002; Karl 2006, 2008), lo cual - siguiendo la definición ofrecida por Wolf (1982) - no quiere decir que las relaciones sociales estuvieran reducidas a las determinadas realmente por el parentesco, sino que todas se expresarían en términos de parentesco, real o ficticio. Como ya apuntó en su día M. Sahlins (1983: 215) desde una perspectiva mucho más general: "El parentesco es lo más importante en la sociedad primitiva, ya que es el principio organizador o la expresión organizadora de la mayor parte de los grupos y de las relaciones sociales". Dejando de lado el desafortunado uso de la expresión "sociedad primitiva", la reflexión de Sahlins parece perfectamente aplicable al mundo de la Edad del Hierro.

La mejor evidencia para rastrear las relaciones de parentesco y los linajes en la Edad de Hierro proviene de los cementerios. Aunque el registro arqueológico está a menudo abierto a múltiples interpretaciones, se ha podido argumentar convincentemente en algunos casos que ciertas agrupaciones de tumbas dentro de los cementerios representaban linajes diferentes. Durante el tiempo de los oppida en los siglos II-I a.n.e. las tumbas son generalmente escasas en la Europa templada, pero en aquellas regiones en las que tenemos un buen registro funerario, algunos ejemplos muestran la existencia del culto a los antepasados durante generaciones o incluso siglos (Fernández-Götz 2016; Metzler 2006). Un buen ejemplo de ello es la necrópolis de Wederath en el Hunsrück (Alemania occidental), donde la distribución espacial de los recintos funerarios de La Tène permite distinguir cinco grandes grupos de enterramiento, donde cada uno presenta su propia historia y evolución que podría reflejar principalmente diferentes grupos familiares (Cordie 2006; Verger 2009). Algunos de ellos parecen estar organizados alrededor de túmulos antiguos, que tal vez habrían sido considerados monumentos funerarios de los antepasados fundadores de los linajes. Indicios similares se aprecian en las necrópolis celtibéricas de la Meseta, donde las tumbas no sólo se disponen formando grupos bien diferenciados espacialmente sino también en lo que a la composición material de los ajuares se refiere. Además, se han podido observar evidencias de culto a los antepasados como demuestran las ofrendas cerámicas sobre las tumbas de Numancia o las armas sobre las de Carratiermes (c.f. Liceras-Garrido en prensa).

En este marco socio-ideológico, la organización de cuestiones comunitarias como la regulación del acceso y la explotación de los 
recursos, así como otros asuntos relacionados con aspectos tales como la defensa colectiva o la administración de justicia, se tratarían principalmente mediante la celebración de asambleas y consejos a diversos niveles (Fernández-Götz 2013b). Esto implicaría desde reuniones locales a otras que podrían abarcar una civitas completa, tal y como menciona Apiano (Iber. 100) para la ciudad celtibérica de Belgeda, y César para Tréveros, Eduos ( $B G \mathrm{~V}$, 56 , VII, 33) e incluso una confederación mucho más larga como es el caso del concilium commune Belgarum o asamblea general de los pueblos belgas ( $B G$ II, 4, 4).

Las asambleas públicas en particular son conocidas a partir de referencias dispersas desde la Galia a Iberia, actuando como mecanismos rectores de gobiernos colectivos similares a las Things escandinavas medievales (Sanmark et al. 2015-16) o el Óenaig irlandés (Gleeson 2015). En un mundo eminentemente rural, caracterizado frecuentemente por las dificultades de transporte, las personas aprovecharían estos encuentros multitudinarios para tratar asuntos religiosos, sociales, económicos y políticos al mismo tiempo (Ligt y Neeve 1988). Presentarían una oportunidad para conocerse, intercambiar bienes e información, así como para establecer o reforzar vínculos sociales, organizar matrimonios o asistir a ceremonias religiosas. En muchos casos, se trataría de autenticas "ferias-fiestas-asambleas" (Alberro 2006), constituyendo las principales arenas de negociación del poder y el momento en el que tomar importantes decisiones colectivas como establecer nuevas leyes, elegir líderes o declarar una guerra (Fernández-Götz 2013b).

El resultado se enmarca dentro del modelo de estructura vecinal propuesto por Torres-Martínez (2011, 2014). Por estructura vecinal se entiende aquella que se sitúa por encima del marco de las relaciones puramente gentilicias: se trata, por tanto, de relaciones de carácter suprafamiliar, por mucho que pudieran ser expresadas en un lenguaje de parentesco metafórico. La articulación política del territorio se construye a través de la combinación de estos dos ámbitos básicos de relación, el gentilicio y el vecinal. En cualquier caso, las formas de relación gentilicias determinarían de forma sustancial el funcionamiento político de las asambleas, entre otras cosas por la participación en ellas de los cabezas de familia.

\section{El surgimiento de las ciudades: los oppida como espacios de agregación}

Para la Edad de Hierro final, el descubrimiento arqueológico de espacios públicos, a menudo asociados a santuarios, y ciertas menciones en las fuentes escritas, tanto en la Galia como en Iberia, permiten sugerir que al menos algunas de las asambleas generales y reuniones del consejo tuvieron lugar dentro de los grandes asentamientos fortificados conocidos como oppida. Estos sitios surgieron en numerosas áreas de la Europa templada en los siglos inmediatamente anteriores a la conquista romana, desde finales del siglo III a.n.e. en el centro-norte de Iberia (Ruiz Zapatero 2011) y, predominantemente, desde finales del siglo II a.n.e. en Galia y Europa Central (Fernández-Götz 2018; Fernández-Götz et al. 2014; Fichtl 2005).

Los oppida no fueron una categoría de asentamiento homogénea y presentan numerosas diferencias relativas al tamaño (desde menos de 10 ha a varios centenares, o incluso más de 1,000 ha), cronología (de una o dos generaciones a largas secuencias de habitación) y funciones (desde centros de producción a sitios con escasa evidencia de ocupación interna). Sin embargo, la mayoría de ellos tienen una serie de rasgos comunes que nos permiten clasificarlos como "ciudades", ya que albergaron un número significativo de población de modo permanente, que puede contabilizarse desde varios cientos a varios miles de habitantes; constituyeron verdaderos centros de producción y comercio; y representaron uno de los principales escenarios para la celebración de las asambleas políticas y ceremonias religiosas. Testimonios como los de Apiano (Iber. 100) y Plutarco (Vidas Paralelas VI, 6) sobre la existencia de lugares de reunión del consejo en las ciudades de Belgeda y Numancia o grandes espacios públicos como los excavados en Titelberg (Metzler et al. 2016) y Corent (Poux y Demierre 2016) así como el presumible santuario a Teutates y el graderío rupestre de Tiermes (Almagro Gorbea y Lorrio 2011) dan fe de este último aspecto (Figura 4). Además, por lo general, los oppida se construyeron en lugares con extensas biografías simbólicas, cuyos enclaves habían servido previamente como lugares de reunión ritual para comunidades dispersas antes de su desarrollo como asentamientos de referencia en el paisaje (Fernández-Götz 2014b; Metzler et al. 2006). 


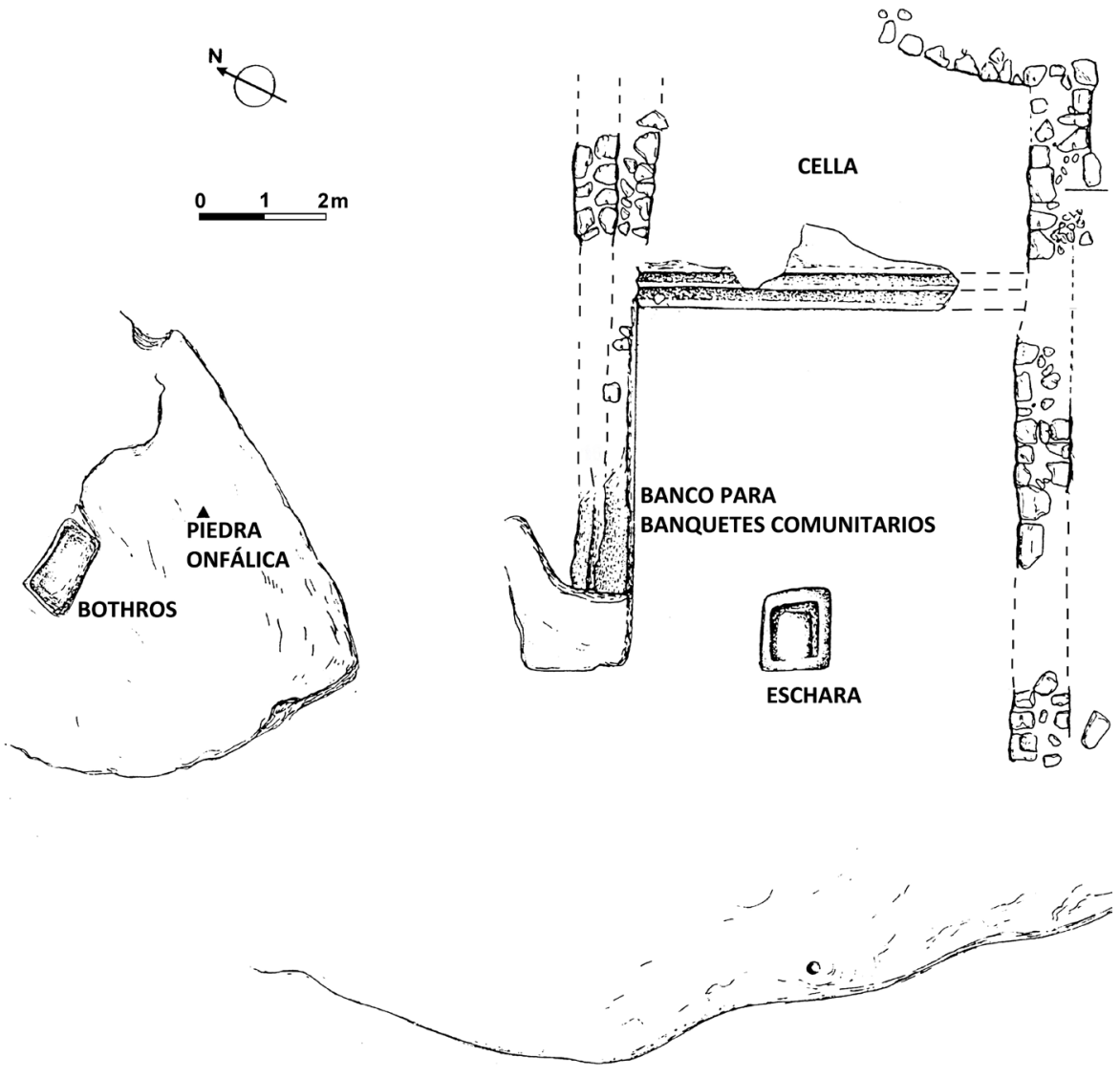

Figura 4: Plano del templo poliádico de Tiermes dedicado al héroe fundador (según Almagro-Gorbea 2016).

Entre las principales características de los oppida se encuentran la existencia de diferentes barrios y de grandes espacios no construidos dentro del perímetro de las murallas. Incluso aquellos sitios con una ocupación y población internas significativas (como Manching, Bibracte, Corent, Titelberg y Ulaca) presentan grandes áreas libres dentro del espacio fortificado, por lo que algunos autores han clasificado los oppida dentro del llamado modelo de "urbanismo de baja densidad" (Moore 2017). Estas grandes áreas abiertas parecen haber jugado un papel fundamental en la negociación del control de las personas y los recursos, por ejemplo, como espacios para guardar el ganado, desarrollar tareas agrícolas, celebrar ferias y asambleas, y también ofrecer refugio para la población rural de un amplio entorno en caso de peligro. Más aún, en numerosas aglomeraciones, sobre todo de la Europa Central, la unidad básica de asentamiento fueron las granjas cercadas, lo que indica una transferencia de modelos rurales a espacios delimitados por murallas (Figura 5). En otras palabras, el interior de los centros urbanos sería una reproducción del panorama territorial, seguramente en muchos casos con grupos de parentesco extensos habitando diversas áreas dentro de los recintos fortificados. Este fenómeno sugiere la nucleación de parte de la población rural y una concentración de actividades que antes se dispersaban más ampliamente en el paisaje. 


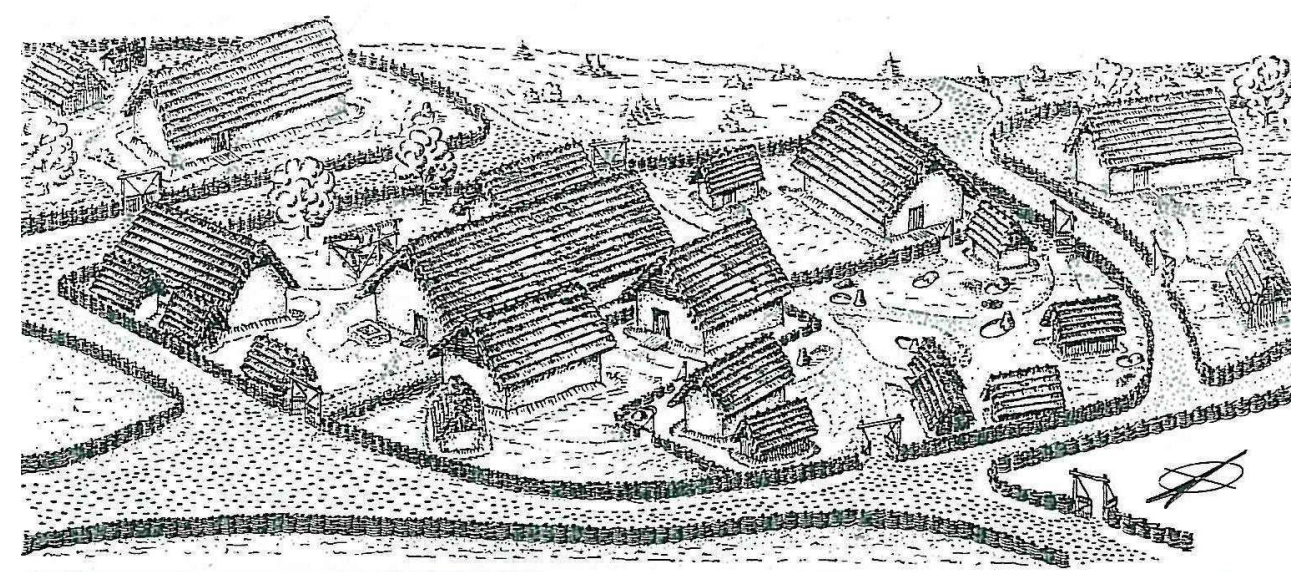

Figura 5: Reconstrucción idealizada de un sector de hábitat en el oppidum de Staré Hradisko (según Fichtl 2005).

Las interrelaciones entre ciudades y mundo rural deben haber sido intensas y diversificadas, ya que, en particular, las primeras no se pueden entender sin el segundo. A pesar del desarrollo de una serie de ciudades, la Edad del Hierro final siguió siendo un mundo fundamentalmente rural, donde la gran mayoría de la población vivía dispersa por el campo (Buchsenschutz 2006; Cowley et al. 2019). Un buen ejemplo de la existencia de múltiples formas de poblamiento rural lo encontramos en el Alto Duero. Sobre esta zona, los autores grecolatinos mencionan términos como megalaskomas (aldeas de gran extensión), vicos castellae (asentamientos medianos), agri (asentamientos de hábitat disperso centrados en la explotación de la tierra), turres, pyrgoi y speculae (sitios dedicados a la defensa y la vigilancia) (Rodríguez Blanco 1977). Arqueológicamente, se han podido identificar tres tipos diferentes de asentamientos rurales: los castillos, asentamientos de 1-3 ha emplazados en localizaciones estratégicas o en las periferias de los territorios, en su mayoría protegidos por poderosas defensas; los poblados, sitios de amplias dimensiones que se alzan sobre lugares prominentes, ejerciendo un punto intermedio en la jerarquía territorial entre las ciudades (oppida) y las aldeas; y finalmente estas últimas, pequeños enclaves inferiores a media hectárea que se sitúan en torno a los poblados y a la ciudad, encargados de la explotación agrícola y ganadera de los recursos (Figura 6) (Liceras-Garrido 2014 y en prensa; Jimeno y Arlegui 1995).

En cualquier caso, son los oppida los que habrían actuado como puntos nodales para el intercambio y la interacción de los territorios en la Europa templada de los siglos II-I a.n.e. Su importancia va más allá del número de personas que vivieron permanentemente dentro de sus perímetros amurallados. Estas ciudades fortificadas actuaron como lugares centrales de agregación para un entorno rural más amplio, sirviendo como elementos de referencia y puntos focales para la creación de identidades colectivas a través de las actividades y actuaciones que se llevaron a cabo en ellos, desde ferias y mercados a reuniones políticas y religiosas. Paralelamente, la evidencia arqueológica sugiere que buena parte de la elite social siguió viviendo, al menos durante gran parte del año, en el ámbito rural más que en el interior de los oppida fortificados (Adam y Fichtl 2014). Tal y como fue el caso de períodos históricos posteriores, gran parte del poder económico, político y social permaneció firmemente anclado en el mundo rural (Crumley 1995). 

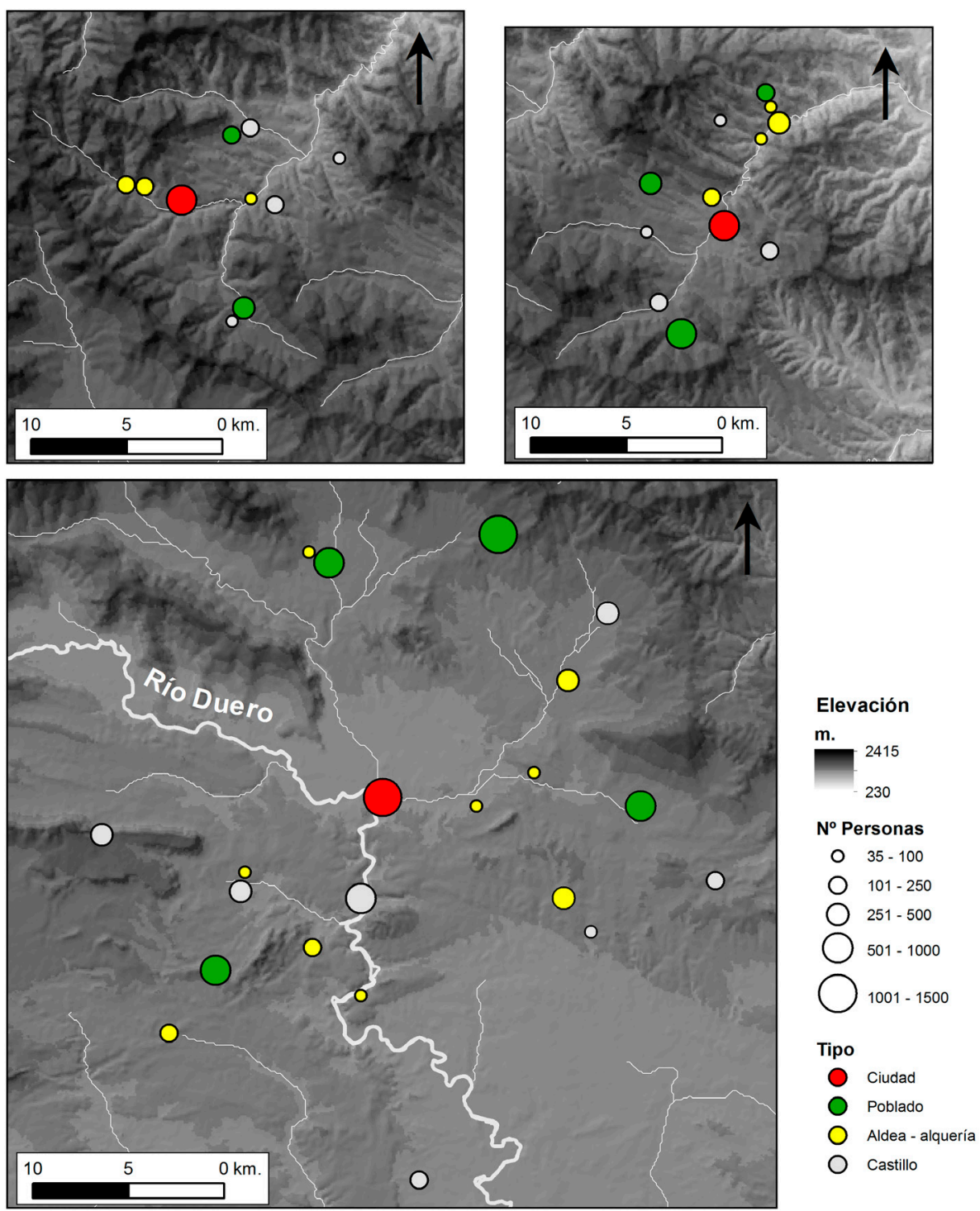

Figura 6: Alto Duero. Distribución del poblamiento protohistórico urbano y rural para los territorios de Numancia (abajo), Los Casares (San Pedro Manrique) (arriba-derecha) y El Castillo (La Laguna) (arriba-izquierda) (según Liceras Garrido).

Como se indicó anteriormente, los oppida fueron lugares de congregación para los habitantes de territorios más amplios, con espacios para que las personas se reunieran y realizaran una amplia variedad de actividades. Los mecanismos que regulan el flujo de relaciones entre los habitantes de los asentamientos rurales y urbanos podrían haberse basado en la existencia de entidades sociales transversales apoyadas por relaciones reales o imaginarias, en las que el parentesco, la familia y el linaje podrían jugar un papel fundamental a la hora de regular las interacciones, la organización social y administrativa y la planificación. Es muy posible, por ejemplo, que algunas familias extensas tuvieran residencias tanto dentro como fuera de los oppida y que sus bases de poder y subsistencia permanecieran en el campo en forma de tierra y ganados, mientras que al mismo tiempo participaran regularmente o periódicamente en las actividades sociales y productivas llevadas a cabo en los centros urbanos nacientes. 
5. La comunidad de villa y tierra de la Soria medieval: ¿una analogía útil para comprender las sociedades del final de la Edad de Hierro?

Llegados a este punto, pensamos que una mirada a la comunidad de "villa y tierra" de la Soria medieval puede proporcionar algunos elementos interesantes de reflexión sobre cómo las sociedades tardías de la Edad de Hierro podrían haber funcionado, al menos parcialmente. $\mathrm{Si}$ bien no estamos proponiendo en ningún momento hacer una comparación directa, ni extrapolar el modelo medieval de una manera literal a la Edad de Hierro, creemos que puede servir como un ejemplo que expanda nuestro corpus de analogías empleadas más allá de los casos peninsulares e insulares irlandeses y britanos que se han utilizado tradicionalmente, presentando al mismo tiempo un valor inspirador. Así, si bien las fuentes irlandesas aún pueden ser una analogía útil para ciertos aspectos, aunque nunca una "ventana" directa a la Edad de Hierro (Jackson 1964), la falta en ellos de centros urbanos representa una limitación para establecer puntos en común con las sociedades de los oppida.

Las comunidades villa y tierra fueron entidades administrativas que surgieron entre los siglos XI y XII en la Extremadura castellana como una forma de organización socio-política y espacial de las tierras conquistadas por los Reinos de Castilla y Aragón. Se han documentado más de 60 de estas comunidades con territorios más o menos extensos y una estructura polinuclear donde personas y espacio quedaban agrupados en collaciones. Las collaciones fueron originalmente grupos familiares extensos que disponían de unos determinados territorios ("la tierra") y tenían su espacio de reunión en la villa. Cada una de las comunidades villa y tierra contó con un número variable de collaciones dependiendo del número de grupos familiares, la extensión de la tierra y las necesidades de movilidad para la subsistencia. Consecuencia de ello es que la comunidad de villa y tierra de Burgos contaba con 14 collaciones, la de Sepúlveda con 15, Ávila 19, Segovia 34 y Soria 35 (Figura 7). En términos de escala, las comunidades de villa y tierra son probablemente comparables a los pagi de la antigua Galia, mientras las collaciones equivaldrían a los grupos familiares o clanes de la Edad de Hierro mencionados al inicio del presente artículo. Este sistema de relaciones de parentesco se basaba en estructuras organizativas transversales, en el que los mecanismos que regularon las interacciones entre collaciones de una comunidad de villa y tierra se pueden explicar mejor siguiendo un modelo de relaciones heterárquico, aunque al mismo tiempo formaron parte de un sistema jerárquico más amplio establecido por las coronas castellana y aragonesa.

En este trabajo nos vamos a centrar en la comunidad de villa y tierra de Soria porque cuenta con una amplia bibliográfica (ver Asenjo 1999; 2012; Martínez Díez 1983) y ha sido utilizada como ejemplo anteriormente para explicar el modelo social de las comunidades de la Edad del Bronce (Asenjo y Galán 2001). Soria era la tercera comunidad de villa y tierra en extensión, contaba con alrededor de 3.000 kilómetros cuadrados -por detrás de Ávila y Segovia-; con más de 300 aldeas y 35 collaciones bajo su jurisdicción (Martínez Díez 2006). Alfonso I el Batallador le concedió derechos a la villa en marzo de 1120 al otorgarle el fuero breve a modo de carta puebla donde quedaba establecido el modelo concejil. Así se constituía una comunidad de villa y tierra cuyo fin era el de repoblar la tierra y reorganizar a la población existente. Esta forma de organización fue fruto del acuerdo entre los diferentes grupos de parentela que poblaban el territorio y los representantes de la monarquía castellano-aragonesa.

Las collaciones estructuraban la vida política, social y religiosa tanto de los núcleos rurales como del urbano. Cada collación estaba compuesta por un grupo de parentesco, de afinidad cognaticia, unido mediante lazos de sangre o determinados pactos o acuerdos (Asenjo 1999; 2012) y contaba con una serie de aldeas distribuidas por la tierra, por lo general entre seis u ocho. La distribución del poblamiento en la tierra de cada una de las collaciones combinaba diferentes aprovechamientos, calidades del suelo y recursos, de modo que la subsistencia del grupo familiar extenso quedase garantizada. Cada collación tenía su propio "barrio" en la villa, cuyo reflejo material era una pequeña reunión de casas, una iglesia parroquial dedicada a su santo patrón y un cementerio (Asenjo 1999; Asenjo y Galán 2001). 


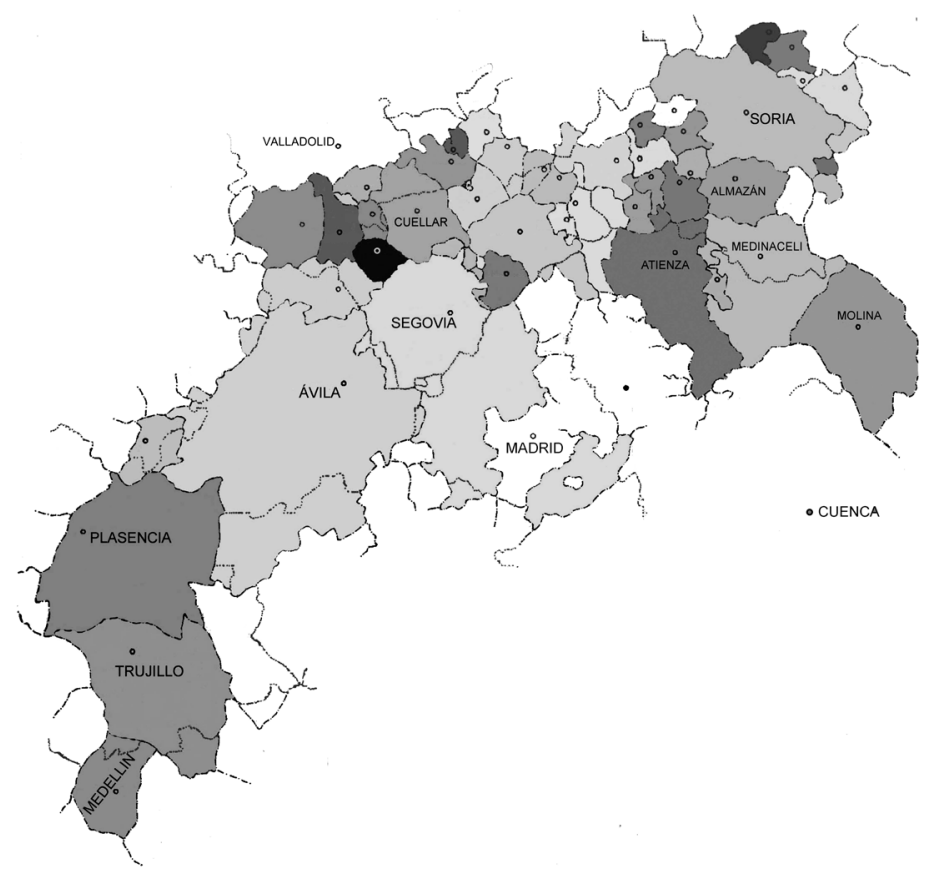

Figura 7: Distribución de las comunidades de villa y tierra en la meseta castellana (según Martínez Díez 1983).

La función principal de la villa de Soria era la de servir como lugar de encuentro para los miembros del grupo familiar extenso y el lugar de encuentro del conjunto de las collaciones. Se trataba del espacio para la socialización, en el que se celebraban bodas, funerales y festivales religiosos y el consejo tomaba sus decisiones. Durante la festividad del día de San Juan, en el solsticio de verano, los habitantes de la tierra de Soria se reunían en la villa, donde establecían sus residencias durante un corto período de tiempo (Asenjo 1999). Construían tiendas o casas con materiales perecederos, llevando consigo sus rebaños y otros bienes. En esta reunión anual se fortalecían los vínculos familiares y sociales, siendo el momento propicio para comerciar, discutir de negocios, establecer pactos y organizar matrimonios. Por ello, el aspecto material que presentaba la villa de Soria era el que un recinto murado de unos $4.000 \mathrm{~m}$ de perímetro que rodeaba los 35 "barrios" cada uno correspondiente a una collación con su parroquia y cementerio, más la Colegiata de San Pedro. El recinto interno comprendía así una extensión de más de 100 ha, cuyas dimensiones permitían dar cabida a todos los habitantes de la tierra (Asenjo 2012) (Figura 8). La ciudad era, por lo tanto, el cen- tro simbólico, el núcleo de la autoridad social y religiosa, donde yacían los restos de los antepasados y el poder en manos de alcaldes y jueces electos entre los miembros de las collaciones y los caballeros villanos.

Cada collación dirimía sus problemas en el seno de la misma como base de la vida política, social y religiosa del grupo familiar, mientras que temas relacionados con el conjunto de las collaciones, como la defensa, serían competencia del órgano superior, el concejo. Esta última institución era de tipo político y administrativo, formada por los miembros de mayor estatus de cada una de las collaciones, siendo en realidad una asamblea de las jerarquías naturales de las parentelas (Asenjo 1999). El concejo se componía de 19 miembros, 18 alcaldes y un juez elegidos entre los miembros de las 35 collaciones. Las funciones de los alcaldes consistían en atrapar a los malhechores e impartir justicia, mientras el juez gozaba de poder ejecutivo con potestad para convocar el concejo, dirigir las milicias y recaudar impuestos. Además, hubo una gran variedad de cargos que velaban por el buen funcionamiento de la comunidad, como un sayón, escribanos públicos, pesquisidores o andadores entre otros (Asenjo 2012). 
La movilidad de la gente entre la villa y los diferentes enclaves de la tierra fue una de las estrategias clave para la supervivencia, debido fundamentalmente a la falta de medios técnicos y la mala calidad de los suelos. En palabras de María Asenjo (1999: 49): "los pobladores de la Tierra de Soria estando muy relacionados con la villa, ya que mantenían fuertes vínculos familiares y sociales en el marco de la collación, mientras vivian en sus aldeas, donde criaban su ganado y establecían sus cultivos". El paso del tiempo dio lugar a una progresiva pérdida de esta movilidad, debido al establecimiento permanente de la población en las aldeas de la tierra, lo que provocó el desarraigo entre los pobladores de la villa y la tierra. Debido a esta paulatina sedentarización surgieron problemas de jurisdicción entre los clérigos parroquianos de las iglesias de la villa de Soria y los eclesiásticos de las aldeas diezmeras, ya que los habitantes de las aldeas se negaban a pagar los diezmos de las iglesias de la villa. El conflicto desembocó en la elaboración de un censo de población en el año 1270 por orden de Alfonso X el Sabio para controlar y facilitar el reparto de los diezmos y la recaudación de otros impuestos (Asenjo 1999).
El censo de 1270 es un documento fiscal diseñado para contabilizar el número de contribuyentes. El elemento clave que compila es el grado de movilidad de la población, ya que a partir de ésta podía conocerse el grado de integración que tenía una persona con la collación y el grado de vinculación que tenía con la villa y la aldea. Así, el censo recoge tres tipos de diezmeros o contribuyentes. En primer lugar, los denominados como vecinos quienes son aquellos que han permanecido asentados en el mismo enclave a lo largo de generaciones. En segundo lugar, los moradores que no residen durante todo el año en la misma ubicación. Por último, los atemplantes o acomendados quienes tienen una gran libertad de desplazamiento, incluso entre collaciones, rompiendo con la rígida estructura parentelar y fomentando el desarraigo familiar en beneficio de los grandes señores (Asenjo 1999). Las mujeres también se encuentran presentes en este censo dentro de las tres categorías, aunque sus figuras están vinculadas generalmente al sedentarismo, próximas a la tierra y a los bienes inmuebles, como garantes de la parentela y sus intereses.

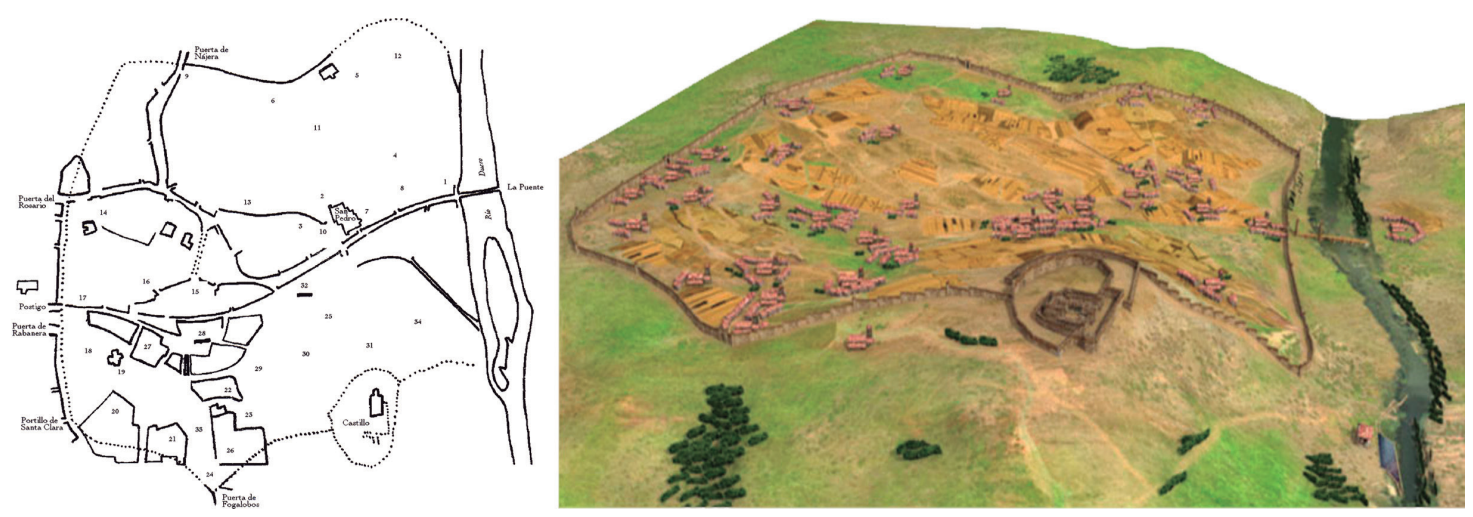

Figura 8: Distribución de las collaciones en la villa de Soria (según Asenjo 1999) y reconstrucción ideal la villa en el siglo XIII, con los diferentes barrios y espacios abiertos (Ayuntamiento de Soria en http://www.soria.es/actualidad/soriavirtuales-una-recreacion-de-la-ciudad-y-sus-monumentos-en-diferentes-momentos-de-la, consultada el 21 de agosto de 2018).

Como punto final del panorama general que presentamos sobre la comunidad de villa y tierra de Soria, hemos de referirnos a los dos principales grupos de poder que se perfilan bajo este marco social: los señores y los caballeros villanos. Los señores fueron los varones de más edad, los principales representantes de los grupos familiares que conformarían las jerarquías naturales. En el fuero de 1256 queda patente su posición social preeminente debido al gran número de menciones que hacen referencia a ellos, así como por la complejidad de su tratamiento. Estos señores ostentaban un conjunto de derechos inherentes a su condición de propietarios y el carácter y tipo de propiedades que poseían eran muy variadas: estaban los señores propietarios de cabañas ganaderas, posiblemente ovinas, denominados los "sennores del gana- 
do"; aunque sin olvidar otros tipos de animales como el "sennor de las gallinas" o el "de las aveias". Los "sennores de los heredamientos" eran aquellos cuya propiedad era la tierra o algún recurso específico como los "sennores de las mieses", los "de las vinnas", los "del uerto" o los "del arbol". El poder de los señores no era tan sólo sobre los recursos, sino también sobre las personas, como queda reflejado en la condición jurídica que establecen con los "iugueros", quienes mantenían una relación de profunda dependencia con los señores mediante acuerdos para realizar determinadas labores. Por otro lado, los caballeros villanos fundaban su estatus sobre dos pilares, propiedades y poder. Eran miembros de la comunidad de origen plebeyo, propietarios de tierras, animales o casas, cuyo verdadero símbolo de su estatus era la posesión de un caballo de guerra y armas. Estos caballeros se encontraban al margen de las estructuras de parentesco y, en algunos casos, tan sólo se les reconoció como acomendados para garantizar la movilidad entre las diferentes parentelas o collaciones. Sus principales obligaciones se relacionaban con la defensa de la villa y la tierra, ocupando cargos tan relevantes como el de "alcaide de la fortaleza de la villa" (Asenjo 1999, 2012).

\section{Reflexiones finales}

¿Qué se puede inferir del modelo de villa y tierra para nuestra comprensión de las sociedades de la Edad del Hierro tardío? Obviamente, hay diferencias importantes que deben tenerse en cuenta, incluido el hecho de que el ejemplo medieval formó parte de una estructura estatal a gran escala, los Reinos de Castilla y Aragón, y una poderosa organización eclesiástica. Tampoco existe una continuidad directa entre los grupos de parentesco medievales y los de la segunda Edad del Hierro de la región de Soria, ya que estuvieron separados por más de 1.000 años y numerosos acontecimientos históricos, incluyendo la dominación romana, el período musulmán y la Reconquista cristiana. Sin embargo, utilizar el modelo villa y tierra como una analogía y no una comparación directa puede llevarnos a algunas reflexiones útiles que nos ayuden a conceptualizar las interrelaciones entre las áreas urbanas y rurales, así como la estructuración simultánea de grupos sociales en torno a los principios de parentesco y territorialidad.
La organización del territorio entre diferentes collaciones, cada una de ellas con propiedades diferentes tanto en el ámbito rural como en el urbano, se asemejaría a un mosaico complejo en el que diferentes grupos de parentesco organizaban sus actividades comunales y de subsistencia de forma no lineal y heterárquica. A pesar de ser parte de un sistema estatal jerárquico, se les concedió un notable grado de autonomía, al menos en las etapas iniciales. Estas formas de redes jerárquicas y no jerárquicas de relaciones personales e interpersonales se integraron en un complejo sistema de interacciones urbano-rurales. Por ello, resulta tentador ver algunas posibles semejanzas con la organización social de la Edad del Hierro tardía en un contexto de urbanismo emergente con el desarrollo de los oppida.

El encuentro estacional de los miembros de las collaciones en la ciudad para celebraciones como la festividad del día de San Juan, con su componente simultáneamente religioso, político y económico, se puede ver como un paralelo a las reuniones colectivas sostenidas periódicamente en los oppida, en particular las grandes asambleas populares. Las personas que pasaban la mayor parte del año en sus residencias de campo iban a los centros fortificados durante algunos días o semanas para participar en eventos comunales más amplios, como una forma de reafirmar su identidad como grupo, pero también para participar como miembros de una entidad socio-política más extensa (Fernández-Götz 2014a).

Yendo un paso más allá, a nivel ideológico, podemos ver ciertas semejanzas entre la veneración de los santos patronos de las collaciones individuales y la adoración precristiana de los "héroes fundadores" de los grupos de parentesco extendidos (Almagro-Gorbea y Lorrio 2011). Desde una perspectiva funcional e incluso material, existen similitudes entre la estructura de los oppida europeos y la ciudad de Soria. Ambos eran los núcleos centrales de los territorios que gobernaban, actuando como centros políticos, administrativos y religiosos. Sus superficies amuralladas eran considerables e incluían espacios abiertos. Se trataba de los principales lugares de reunión y comercio de las comunidades, tenían áreas donde los habitantes del entorno rural podían congregarse y eran las sedes de los principales órganos del gobierno, como consejos y asambleas. En el ejemplo medieval, vimos cómo cada grupo fami- 
liar extendido (collación) estaba representado en la ciudad por un vecindario. La estructura urbana de muchos oppida, tanto en la Galia, Europa Central como en la Meseta española, estaba formada por aglomeraciones de casas que formaban barrios. Estas aglomeraciones pueden haber correspondido a algún tipo de relación entre sus habitantes, más allá de un vecindario simple, quizás a veces indicando lazos de parentesco entre sus miembros de una manera similar a las collaciones medievales. La apropiación del espacio por parte de los constructores y las relaciones dependientes que se habrían establecido entre las diferentes unidades domésticas podrían haberse vinculado a algún tipo de vínculos de parentesco reales o imaginarios.

En resumen, aunque no estamos proponiendo que el modelo de villa y tierra sirva como un paralelo idéntico para las sociedades de los oppida de la Edad de Hierro, creemos que puede constituir una analogía útil que ayude a inspirar nuevas formas de reflexión sobre las evidencias arqueológicas y textuales. Si bien seguramente hay muchas otras analogías históricas y etnográficas apropiadas, esperamos haber proporcionado al menos algunas ideas para reflexionar sobre la difícil pero fascinante tarea de entender a las sociedades de finales del primer milenio a.n.e.

\section{Bibliografía}

Adam, A. M.; Fichtl S. (2014): L'aristocrate des villes et l'aristocrate des champs. En S. Bourdin, J. Dubouloz y E. Rosso (eds) Peupler et habiter l'Italie et le monde romain. Etudes d'histoire et d'archéologie offertes à Xavier Lafon. Presses universitaires de Provence, Aix-en-Provence: 43-52.

Alberro, M. (2006): La feria-fiesta-asamblea óenach de Irlanda y sus posibles paralelos en la antigua Hispania Céltica. Habis 37: 159-181.

Almagro-Gorbea, M. (1995): El urbanismo en la Hispania Céltica: castros y "oppida" en la Península Ibérica. En M. Almagro-Gorbea y A. M Martín (eds.), Castros y "oppida" de Extremadura. Editorial Complutense, Madrid: 13-75.

—(2006): El "Canto de los Responsos" de Ulaca (Ávila): un rito celta del Más Allá. Ilu Revista de Ciencias de las Religiones 11: 5-38.

- (2016): Founding Rituals and Myths in the Keltiké. In M. Fernández-Götz and D. Krausse (eds), Eurasia at the Dawn of History: Urbanization and Social Change. Cambridge University Press, New York: 336-350.

- (2017): El "Medianeto", una institución de origen celta en los Fueros de Extremadura. En J. C. Bermejo Barrera y M. García Sánchez (eds.), Desmoi Filias. Bonds of Friendship. Studies in Ancient History in Honour of Francisco Javier Fernández Nieto. Universitat de Barcelona, Barcelona: 23-42.

- y Almagro-Vidal, C. (2012): De la organización celta cuatripartita del territorio a las "cuadrillas" medievales. En Homenaje al Prof. José García Escudero, IV. Editorial Complutense, Madrid: 37-65.

Almagro-Gorbea, M.; A. Lorrio (2011): Teutates. El Héroe Fundador y el culto heroico al antepasado en Hispania y en la Keltiké. Real Academia de la Historia, Madrid.

Asenjo, M. (1999): Espacio y sociedad en la Soria medieval. Siglos XIII-XV. Diputación Provincial de Soria, Soria.

- (2012): La ciudad de Soria. El concejo medieval y su Fuero. En VIII Encuentro de trabajo sobre historia de la contabilidad. Publicación on-line: http://www.aeca.es/viii_encuentro_trabajo_historia_contabilidad/ponencias/003a.pdf (Consulado 5-4-2019).

—; Galán E. (2001): Formas de asentamiento y organización social del espacio. Un modelo de repoblación medieval: el caso de Soria. Un ejemplo de la aplicación de fuentes medievales al estudio de la Edad del Bronce. En M. Ruiz-Gálvez Priego (ed.): La Edad del Bronce, ¿Primera Edad de Oro de España? Sociedad, economía e ideología. Ed. Crítica, Barcelona: 321-344.

Balbín Chamorro, P. (2013): Un ejemplo de pervivencias jurídicas de la Antigüedad en la Edad Media: las cartas de vecindad ovetenses. En R. M. Cid y E. García (eds.), Debita verba: estudios en homenaje al profesor Julio Mangas Manjarrés 2. Ediciones de la Universidad de Oviedo, Oviedo: 155-172.

Bauchhenss, G (2007): Einheitliche Vielfalt: Der Kult der Matronae im Rheinland. En G. Uelsberg (ed.), Krieg und Frieden. Kelten - Römer - Germanen. Primus Verlag, Darmstadt: 270-272.

Brun, P. (1987) : Princes et Princesses de la Celtique. Le premier âge du fer en Europe 850-450 av. J.-C. Collection Hesperides, París. 
Buchsenschutz, O. (2006): Le monde rural et ses productions (IIe-Ier s. av. J.-C.). En C. Haselgrove (ed.), Celtes et Gaulois, l'Archéologie face à l'Histoire. 4: Les mutations de la fin de l'âge du Fer. Collection Bibracte 12/4. Centre archéologique européen, Glux-en-Glenne: 55-65.

Burillo, F. (2008): Los Celtíberos: étnias y estados. Ed. Crítica, $2^{\mathrm{a}}$ edición, Barcelona.

Clastres, P. (1989): Society Against the State: Essays in Political Anthropology. Zone Books, New York.

Collis, J. (1994): Reconstructing Iron Age Society. En K. Kristiansen y J. Jensen (eds), Europe in the First Millennium BC. J. R. Collis Publications, Sheffield: 31-39.

Cordie, R. (2006): Zu den latènezeitlichen Grabgärten von Wederath/Belginum. En W.-R. Teegen, R. Cordie, O. Dörrer, S. Rieckhoff y H. Steuer (eds), Studien zur Lebenswelt der Eisenzeit. RGA Ergänzungsbd. 53, Berlin/New York: 251-263.

Cowley, D.; M. Fernández-Götz; T. Romankiewicz; H. Wendling (eds.) (2019): Rural Settlement: Relating Buildings, Landscape, and People in the European Iron Age. Sidestone Press, Leiden.

Crumley, C. L. (1995): Building an historical ecology of Gaulish polities. En B. Arnold y D. B. Gibson (eds), Celtic Chiefdom, Celtic State. The evolution of complex social systems in prehistoric Europe. Cambridge University Press, Cambridge: 26-33.

Eggert, M. K. H. (1988): Riesentumuli und Sozialorganisation. Vergleichende Betrachtungen zu den sogenannten „Fürstengrabhügeln“ der späten Hallstattzeit. Archäologisches Korrespondenzblatt 18: 263274.

Fernández-Götz, M. (2013a): Ethnicité, politique et échelles d'intégration: réflexions sur les « pagi » gaulois avant la Conquête. Études Celtiques 39, 7-29.

- (2013b): Politik, Religion und Jahrmärkte: Zur Rolle der Volksversammlungen im eisenzeitlichen und frühmittelalterlichen Europa. En R. Karl y J. Leskovar (eds.), Interpretierte Eisenzeiten 5. Fallstudien, Methoden, Theorie. Tagungsbeiträge der 5. Linzer Gespräche zur interpretativen Eisenzeitarchäologie,. Oberösterreichisches Landesmuseum, Linz: 71-82.

Fernández-Götz, M. (2014a): De la familia a la etnia: Protohistoria de la Galia Oriental. Bibliotheca Archaeologica Hispana 41. Real Academia de la Historia, Madrid.

- (2014b): Sanctuaries and ancestor worship at the origin of the oppida. En V. Sirbu y S. Matei (eds.), Residential Centres (dava, emporium, oppidum, hilfort, polis) and Cult Places in the Second Iron Age of Europe. Mousaios 19. Muzeul Judetean Buzău, Buzău: 111-132.

- (2016): The power of the past: Ancestral cult and collective memory in the Central European Iron Age. In V. Sîrbu, M. Jevtić, K. Dmitrović and M. Ljuština (eds.), Funerary Practices during the Bronze and the Iron Ages in Central and Southeast Europe. University of Belgrade/National Museum Čačak, Belgrade/Čačak: 165-178.

— (2017): Contested Power: Iron Age Societies against the State? En S. Hansen y J. Müller (eds.), Rebellion and Inequality in Archaeology. Habelt, Bonn: 271-287.

- (2018): Urbanization in Iron Age Europe: Trajectories, Patterns and Social Dynamics. Journal of Archaeological Research 26: 117-162.

-; Wendling, H.; Winger, K. (eds) (2014): Paths to Complexity: Centralisation and Urbanisation in Iron Age Europe. Oxbow Books, Oxford.

Fichtl, S. (2005): La ville celtique. Les oppida de 150 av. J.-C. à 15 ap. J.-C. Errance, París.

- (2012): Les peuples gaulois. IIIe-Ier siècle av. J.-C. Errance, París.

Frankenstein, S.; Rowlands, M. J. (1978): The Internal Structure and Regional Context of Early Iron Age Society in South-Western Germany. Bulletin of the Institute of Archaeology 15, 73-112.

García Quintela, M. V. (2002): La organización socio-política de los Populi del Nororeste de la Península Ibérica. Un estudio de antropología política histórica comparada. TAPA, Santiago.

Gerritsen, F.; N. Roymans (2006): Central places and the construction of tribal identities. The case of the Late Iron Age Lower Rhine region. En C. Haselgrove (ed.), Celtes et Gaulois, l'Archéologie face à l'Histoire. 4: Les mutations de la fin de l'âge du Fer. Collection Bibracte 12/4. Centre archéologique européen, Glux-en-Glenne: 251-266.

Gleeson, P. (2015): Kingdoms, Communities, and Óenaig: Irish Assembly Practices in their Northwest European Context. Journal of the North Atlantic 8, 33-51.

González García, F. J. (2017): Exploring Alternative Pathways to Social Complexity in the European Iron Age: The Northwestern Iberian Peninsula as a Case Study. Cambridge Archaeological Journal 27 (2): 295-311. 
Gramsch, A. (ed.) (2000): Vergleichen als archäologische Methode. Analogien in den Archäologien. BAR International Series 825, Oxford.

Haselgrove, C. (1987): Culture Process on the Periphery: Belgic Gaul and Rome During the Late Republic and Early Empire. En M. J. Rowlands, M. T. Larsen y K. Kristiansen (eds), Centre and Periphery in the Ancient World. New Directions in Archaeology, Cambridge: 104-124.

Hill, J. D. y C. G. Cumberpatch (1993): Volviendo a pensar la Edad del Hierro. Trabajos de Prehistoria 50: 127-137.

Hill, J. D. (1995): How Should We Understand Iron Age Societies and Hillforts? A Contextual Study from Southern Britain. En J. D. Hill y C. G. Cumberpatch (eds), Different Iron Ages. Studies on the Iron Age in Temperate Europe. BAR International Series 602, Oxford: 45-66.

- (2006): Are we any closer to understanding how later Iron Age societies worked (or did not work)?. En C. Haselgrove (ed.), Celtes et Gaulois, l'Archéologie face à l'Histoire. 4: Les mutations de la fin de l'âge du Fer. Collection Bibracte 12/4. Centre archéologique européen, Glux-en-Glenne: 169-179.

Ickerodt, U. F. (2010): Einführung in das Grundproblem des archäologisch-kulturhistorischen Vergleichens und Deutens. Peter Lang, Frankfurt am Main.

Jackson, K. H. (1964). The Oldest Irish Tradition: A Window on the Iron Age. Cambridge University Press, Cambridge.

Jimeno, A.; Arlegui, M. (1995): El poblamiento en el Alto Duero. En F. Burillo (coord.): Poblamiento Celtibérico. III Simposio sobre los Celtíberos. Instituto Fernando el Católico, Zaragoza: 93-126.

Karl, R. (2006): Altkeltische Sozialstrukturen. Archaeolingua, Budapest.

- (2008): Feine Unterschiede. Zu «Keltengenese» und ethnogenetischen Prozessen in der Keltiké. Mitteilungen der Anthropologischen Gesellschaft in Wien 138: 205-223.

- (2015): Labour Procurement in Pre-Monetary Europe. En A. Danielisova y M. Fernández-Götz (eds.), Persistent Economic Ways of Living. Production, Distribution, and Consumption in Late Prehistory and Early History. Archaeolingua, Budapest: 21-36.

- (2017): Interpreting Iron Age Societies: A Response to John Collis. En H. Müller (ed.), Keltische Kontroversen II. Computus.

Kümmel, C. (2001): Frühe Weltsysteme. Zentrum und Peripherie-Modelle in der Archäologie. Tübinger Texte 4, Rahden/Westf.

Liceras-Garrido, R. (2014): Sobre el territorio de los numantinos. En J. Honrado, M.A. Brezmes, A. Tejeiro y O. Rodríguez (coords.), II Jornadas de Jóvenes Investigadores del Valle del Duero: del Neolítico a la Antigüedad Tardía. Glyphos Publicaciones: 177-190.

- (en prensa): La Edad del Hierro en el Alto Duero: paisajes, identidades y poder. Diputación Provincial de Soria, Soria.

Ligt, L. de; Neeve P.W. de (1988): Ancient Periodic Markets: Festivals and Fairs. Athenaeum 66: 391-416.

Mann, M. (2012): The Sources of Social Power. Volume 1, A History of Power from the Beginning to AD 1760. Cambridge University Press, Cambridge.

Martínez Díez, G. (1983): Las comunidades de villa y tierra de la Extremadura castellana. Ed. Nacional, Madrid.

- (2006): El fuero de Soria: génesis y fuentes. Anuario de historia del derecho español 76: 9-32.

Metzler, J. (2006): Überlegungen zu den Adelsgräbern der Spätlatènezeit in Gallien. En C. von Carnap-Bornheim, D. Krausse y A. Wesse (eds), Herrschaft - Tod-Bestattung. Zu den vor-und frühgeschichtlichen Prunkgräbern als archäologisch-historische Quelle. Habelt, Bonn: 81-94.

—, C. Gaeng; P. Méniel (2016): L'espace public du Titelberg. Dossiers d'Archéologie du Musée National d'Histoire et d'Art 17, Luxembourg.

Metzler, J., Méniel, P.; Gaeng, C. (2006): Oppida et espaces publics. En C. Haselgrove (ed.), Celtes et Gaulois, l'Archéologie face à l'Histoire. 4: Les mutations de la fin de l'âge du Fer. Collection Bibracte 12/4. Centre archéologique européen, Glux-en-Glenne: 201-224.

Moore, T. (2017): Beyond Iron Age 'towns'. Examining oppida as examples of low-density urbanism. Oxford Journal of Archaeology 36 (3), 287-305.

Moya Maleno, P. (2013): Paleoetnología de la Hispania Céltica. Etnoarqueología, Etnohistoria y Folklore como fuentes de la Protohistoria. Tesis Doctoral inédita de la Universidad Complutense, Madrid.

Peralta, E. (2003): Los Cántabros antes de Roma. Bibliotheca Archaeológica Hispana 5. Real Academia de la Historia, Madrid. 
Poux, M. ; Demierre M. (ed.) (2016). Le sanctuaire de Corent (Puy-de-Dôme, Auvergne) Vestiges et rituels. Supplément à Gallia, París.

Roymans, N. (1990): Tribal Societies in Northern Gaul. An Anthropological Perspective. Cingula 12, Amsterdam.

Ruiz-Zapatero, G. (2011): El caleidoscopio urbano en el mundo 'céltico' de la Meseta. En J. R. Álvarez-Sanchís, A. Jimeno y G. Ruiz-Zapatero (eds), Aldeas y ciudades en el primer milenio a.C. La Meseta Norte y los origenes del urbanismo. Complutum 22 (2): 297-309.

Ruiz-Zapatero, G. (2017): La organización socio-política en Carpetania septentrional en vísperas de la conquista romana. En Vides Monumenta Veterum: Madrid y su entorno en época romana. Zona Arqueológica, 20 (vol.I), Madrid: 103-115.

—; Fernández-Götz, M. (2009): «Trianguläre» und kriegerische Gesellschaften in der Eisenzeit des «keltischen Hispaniens»? Auf der Suche nach der Vielfalt eisenzeitlicher Sozialstrukturen. En R. Karl y J. Leskovar (eds), Interpretierte Eisenzeiten 3. Fallstudien, Methoden, Theorie. Oberösterreichisches Landesmuseum, Linz: 99-112.

Sahlins, M. (1983): Economía de la Edad de Piedra. Akal, Madrid.

Sanmark, A., Iversen, F. ; Mehler, N.;Semple, S. (eds) (2015-16): Debating the Thing in the North II. Journal of the North Atlantic 8, Special Volume.

Sastre, I. (2002): Forms of social inequality in the Castro Culture of north-west Iberia. European Journal of Archaeology 5 (2), 213-248.

Torres-Martínez, J. F. (2011): El Cantábrico en la Edad del Hierro: medioambiente, economía, territorio y sociedad. Real Academia de la Historia, Madrid.

- (2014): Estructura territorial, relaciones vecinales y gobierno de las comunidades en el norte de La Península Ibérica en la Edad del Hierro. Complutum 25 (1): 177-201.

Thurston, T. (2009): Unity and Diversity in the European Iron Age: Out of the Mists, Some Clarity? Journal of Archaeological Research 17 (4), 7-84.

Verger, S. (2009): Société, politique et religion en Gaule avant la Conquête. Éléments pour une étude anthropologique. Pallas 80, 61-82.

Wallerstein, I. (1974): The Modern World-System. Academic Press, New York/London.

Wolf, E. R. (1982): Europe and the People without History. University of California Press, Berkeley. 